\title{
Improving Mathematical Learning by the Use of Computer Programming
}

\author{
Nachayapat Rodprayoon ${ }^{1}$, Chompu Nuangjamnong ${ }^{2} \&$ Stanislaw Paul Maj $^{3}$ \\ 1 Faculty of Business Administration, Rajamangala University of Technology Thanyaburi, Pathum Thani, \\ Thailand \\ ${ }^{2}$ Faculty of Business Administration, Saint John's University, Bangkok, Thailand \\ ${ }^{3}$ Engineering Institute of Technology, Perth, Western Australia \\ Correspondence: Nachayapat Rodprayoon, Information Systems Department, Faculty of Business Administration, \\ Rajamangala University of Technology Thanyaburi, 39 Moo 1, Rangsit-Nakhonnayok Rd. (Klong6), Thanyaburi \\ Pathum Thani, Thailand. Tel: 66-0-2549-3241. E-mail: nachayapat_r@rmutt.ac.th
}

Received: January 27, 2018

Accepted: February 8, $2018 \quad$ Online Published: March 20, 2018

doi:10.5539/mas.v12n4p83

URL: https://doi.org/10.5539/mas.v12n4p83

\begin{abstract}
Computer technology is now an integral aspect of modern life. It is also a tool that can support the learning of different disciplines. Computer technology provides the possibility to display rich graphical images which may be especially important when teaching different branches of mathematics such as trigonometry. An on-screen image (diagram) clearly demonstrates the relationship between key learning points and how they interact. Furthermore, the dynamic nature of the associated program supports interactive learning in which the parameters may be modified and the result displayed - which is basis of the constructivist theory of pedagogy. This paper is a quantitative and qualitative analysis of the use of computer science as a tool to improve the teaching of trigonometry.
\end{abstract}

Keywords: mathematical education, computer programming

\section{Introduction}

The analysis of the role of technology is examined on the basis of the experience developed in the implementation and evaluation of computer-based visualization for teaching and learning trigonometry. It is a theory-based analysis of the empirical material gathered from this experimental work, which involved the use of application program in teaching trigonometry in Faculty of Business Administration, Rajamangala University of Technology Thanyaburi, Pathum Thani, Thailand. The theoretical frame of the research was constructed based on the relation of three components: the subject of Information Technology unit, the use of technology and the cognitive theory of learning. This relation consists in the use of technology during computer technology lessons in order to foster students' understanding from a cognitive point of view. Technology and cognition are related by the principle of cognitive technologies, described by (Pea, 1987), who suggests that technology should be used as cognitive tools for learning purposes. Computer technology and cognition are related by the constructivist theory of learning, which emphasizes the student-centered model of learning. Finally, the most important relation is the one of computer hardware content, which, when used during the teaching and learning process, helps students to visualize better the computer technology content, to link different representations of microprocessor objects and procedures and promote conceptual understanding through concretization and real-life context.

\section{Method}

\subsection{The Role of Technology Integration in Relation to Learning Theoretical Framework}

The theoretical framework constructed for this study is divided into two main components: the integration of the computer program in computer technology teaching and learning, and the investigation of the role of such practices in students' achievement. The first component is related to the use of multiple representations in computer technology teaching and learning (Duval, 1999) and the use of the program as a cognitive tool (Pea, 1987). The second component is based on the three types of understanding of computer technology (Skemp, 1979) and the constructivist theory of learning. Researchers on cognition and pedagogy emphasize constructivist approaches as an important learning theory. This theory emphasizes the cognitive process of learning, focusing 
on the connection between prior and new knowledge. (Grabinger, Dunlap, \& Duffield, 1995), in their study about supporting constructivist learning by multimedia, characterize constructivism by three different aspects. In the following paragraph we take a look at these three aspects and analyses how technology practices can help in this learning approach:

\subsubsection{Learning is an Active and Evolving Process}

Constructivist models of learning strive to create environments where learners are active participants, in a way to help them construct their own knowledge, rather than having the teacher interpret the world and insure that students understand the world as they have told them. The constructivist model is defined as a student-centered model and it is better aligned with the goals of the school reform. Another important principle related to active learning is the one developed by Dewey, "learning by doing" (Dewey, 1933), which was later defined by Bruner (Faugli, 2003) as "discovery learning". Since technology supports this kind of learning model by offering students interaction with the tool, its importance in the education process is obvious. It allows students to work more meaningfully with tasks and engages them in knowledge construction rather than knowledge reproduction (Jonassen, 1994).

\subsubsection{The Context is Significant in the Building of Knowledge}

It is very important for students to build their knowledge in rich environments, related to situations where they can apply and try what they learn. What students learn should not be separated from how they learn it (Brown et al. 1998 and Kaur 2000, in Faugli, p.16). As mentioned above, Ashburn and Floden (op. cit.) emphasize the role of technology by showing how it can help for a better learning experience, connecting school with real world. In this way, students will be able to transfer the knowledge constructed during the lessons to other situations out of the classroom.

2.1.3 The Social Context in Which the Learning Takes Place is of Great Importance to Conceptual Development and Takes Place by Sharing Ideas and Testing Ideas with others.

This can be related to the social-cultural theory developed by (Vygotsky, 1978), which states that students learn through socially mediated activities where they discuss and discover concepts from different perspectives under teacher's facilitation. As technology supports interaction and collaborative learning (Ashburn \& Floden, 2006), it helps to promote meaningful learning and makes it easier for students to engage in their knowledge construction.

Inspired by cognitivist theories, the diagram framework has been formulated to present the structure of the research conceptual framework (Figure 1).

\section{Computer Technology}
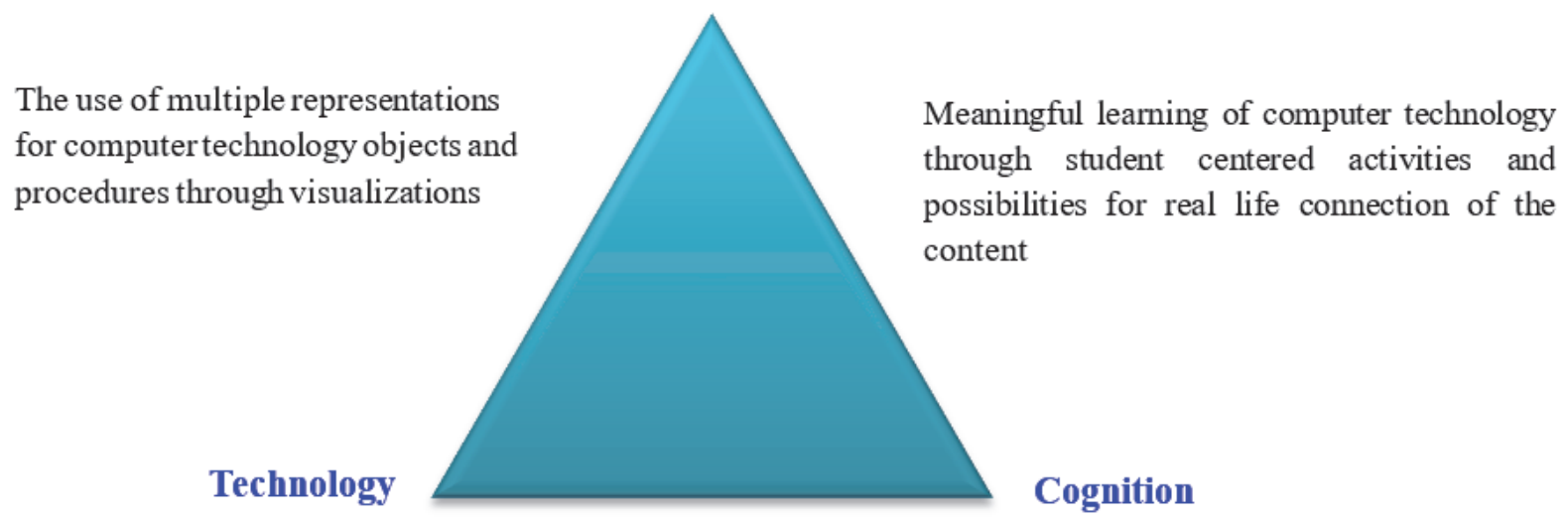

The use of the program as a cognitive tool:

- Interactive, support exploration

- Link different representations / Fluent in routine tasks

Figure 1. The structure of the theoretical framework

This study is to investigate the role of the computer program in teaching and learning trigonometry in department of computer in business program. In order to achieve this aim, a mixed method research design has been used 
(Johnson \& Onwuegbuzie, 2004), including a number of data collection instruments, such as: pre- and post- tests, self-completion questionnaires, direct observations (videotaped) and interviews(audiotaped). Both quantitative and qualitative approaches offered beneficial attributes in this study to investigate the effectiveness of technology implementation. The quantitative approach helped to assess students' understanding and learning of the concepts explored with computer program according to the scores earned. The qualitative approach afforded the opportunity to analyses a wide variety of data, including interviews and feedback of students in order to define their attitudes and to make a qualitative analysis of their work (through a test and class work), comparing solutions between the two groups.

\subsection{Participants}

Twenty-two students from the Computer in Business program (18-22 years old) of the Faculty of Business Administration, Rajamangala University of Technology Thanyaburi participated in this study of which half were female. Participation in the experimental lessons was entirely optional. All the students were informed beforehand about the procedure and the purpose of the experiment, and only those who agreed participated in it. They were also informed about their privacy and that the data would be used for research purposes only. The videos were only to be used to conduct this research, and the names on tests and questionnaires were to be coded with numbers.

\section{Results}

\subsection{The Role of Computer Program in Teaching and Learning Numeral Systems}

The activities for the use of computer program during the lesson were organized according to three main purposes of using a tool in the teaching and learning process (Wilson, 2008), relating them to some important pedagogical benefits. These activities are shown in table 1. Also demonstrated are some of the computer program interfaces where these activities took place.

Table 1. Presentation of activities using computer program in relation to the pedagogical purpose of its use

\begin{tabular}{|c|c|c|c|}
\hline $\begin{array}{l}\text { Stage } \\
\text { No. }\end{array}$ & $\begin{array}{l}\text { Purpose of } \\
\text { using the tool }\end{array}$ & $\begin{array}{l}\text { Trigonometry lessons activity } \\
\text { using computer program }\end{array}$ & Pedagogical benefits \\
\hline \multirow[t]{3}{*}{1} & \multirow[t]{3}{*}{$\begin{array}{l}\text { Promoting drill } \\
\text { and practice }\end{array}$} & $\begin{array}{l}\text { Conversion between } \\
\text { measurement of binary digits }\end{array}$ & \multirow{3}{*}{$\begin{array}{l}\text { - } \quad \text { Reduction of time required to practice basic } \\
\text { skills } \\
\text { - } \quad \text { All students engaged during the lessons }\end{array}$} \\
\hline & & $\begin{array}{l}\text { Calculation of the values of binary digits } \\
\text { for different computer digit number }\end{array}$ & \\
\hline & & $\begin{array}{l}\text { Presenting the graphs and data of } \\
\text { computer digit number }\end{array}$ & \\
\hline \multirow[t]{2}{*}{2} & \multirow[t]{2}{*}{$\begin{array}{l}\text { Variation of } \\
\text { parameters }\end{array}$} & $\begin{array}{l}\text { Changing parameters of computer digit } \\
\text { number and looking at the changes in the } \\
\text { graphical characteristics }\end{array}$ & \multirow{2}{*}{$\begin{array}{l}\text { - Immediate response is effective to make the } \\
\text { connection between the parameters in computer digit } \\
\text { number and helps to construct a mental model of how } \\
\text { a variable affects the graphical representation }\end{array}$} \\
\hline & & $\begin{array}{l}\text { Exploring and discovering the meaning of } \\
\text { amplitude and period, changing the values } \\
\text { of parameters in the computer digit } \\
\text { number }\end{array}$ & \\
\hline 3 & $\begin{array}{l}\text { Conceptual } \\
\text { understanding }\end{array}$ & $\begin{array}{l}\text { Doing and presenting the same problem in } \\
\text { the hexadecimal(base } 16(\text { systems and } \\
\text { graphical representation }\end{array}$ & $\begin{array}{l}\text { - Emphasis on understanding instead of } \\
\text { memorizing the algorithm for solving problems }\end{array}$ \\
\hline
\end{tabular}

As it can be noticed from table 1, the pedagogical benefits are related to the three important principles of cognitive learning:

- Active learning of students,

- Exploring and discovering by themselves functions properties,

- Meaningful learning through concretization.

\subsection{Pre and Post Test Results}

After evaluating the pre- and the post-test results for both groups, we organized the scores in tables and using the program spread sheet application, we made a descriptive analysis of the results, showing the means, the standard 
deviations, the standard error means and the graphical representations. In tables 2 and 3, we show the results of the pre- and post-test for the two groups and the mean of the results. To compare the performance of students in the post-test with the one in the pre-test, we calculated the difference of the results, subtracting from the post-test scores the pre-test scores.

Table 2. Pre and post test scores in the experimental group

\begin{tabular}{|c|c|c|c|}
\hline Experimental No. & Pre-test & Post-test & Different \\
\hline 1 & 72 & 87 & 15 \\
\hline 2 & 90 & 97 & 7 \\
\hline 3 & 67 & 75 & 8 \\
\hline 4 & 78 & 82 & 4 \\
\hline 5 & 72 & 75 & 3 \\
\hline 6 & 70 & 82 & 12 \\
\hline 7 & 71 & 87 & 16 \\
\hline 8 & 70 & 81 & 11 \\
\hline \multicolumn{4}{|c|}{$\begin{array}{l}\text { Table 2. Pre and post } \\
\text { experimental group(Cont.) }\end{array}$} \\
\hline Experimental No. & Pre-test & Post-test & Different \\
\hline 9 & 79 & 97 & 18 \\
\hline 10 & 72 & 80 & 8 \\
\hline $11 *$ & 50 & 43 & -7 \\
\hline Mean & 71.91 & 80.55 & 8.64 \\
\hline
\end{tabular}

Table 3. Pre and post test scores in the control group

\begin{tabular}{llll}
\hline Control No. & Pre-test & Post-test & Different \\
\hline 1 & 63 & 70 & 7 \\
\hline 2 & 68 & 79 & 11 \\
\hline 3 & 90 & 92 & 2 \\
\hline 4 & 60 & 68 & 8 \\
\hline $5^{*}$ & 73 & 72 & -1 \\
\hline $6^{*}$ & 66 & 44 & -22 \\
\hline $7 *$ & 88 & 86 & -2 \\
\hline 8 & 81 & 96 & 15 \\
\hline
\end{tabular}

Table 3. Pre and post test scores in the control group(Cont.)

\begin{tabular}{llll}
\hline Control No. & Pre-test & Post-test & Different \\
\hline 9 & 68 & 81 & 13 \\
\hline 10 & 58 & 84 & 26 \\
\hline 11 & 55 & 62 & 7 \\
\hline Mean & 70.00 & 75.82 & 5.82 \\
\hline
\end{tabular}

In general, both groups had higher performance in the post-test, compared to the pre-test results. But in the experimental group, we can show that the average of the difference between the pre-test and post-test is 8.64, which is considerably higher than the one in the control group of 5.82. This indicates that the students in the experimental group improved more in the post-test than students in the control group. Only one participant in the experimental group, experimental no 11 and three participants in the control group which had lower performance in the post test. In table 4 and table 5 are presented the descriptive statistics of the two groups(means, standard deviations and standard error means).

Table 4. Descriptive statistics of pre-test scores

\begin{tabular}{lcccc}
\hline \multicolumn{1}{c}{ Group } & N & Mean & $\begin{array}{c}\text { Std. } \\
\text { Deviation }\end{array}$ & $\begin{array}{c}\text { Std. } \\
\text { Err M }\end{array}$ \\
\hline Pre-test & & & & \\
\hline Exp Group & 11 & 71.91 & 9.63 & 4.4 \\
\hline Control Group & 11 & 70.00 & 11.82 & 4.1 \\
\hline
\end{tabular}

Table 5. Descriptive statistics of post-test scores

\begin{tabular}{lcccc}
\multicolumn{1}{c}{ Group } & N & Mean & $\begin{array}{c}\text { Std. } \\
\text { Deviation }\end{array}$ & $\begin{array}{c}\text { Std. } \\
\text { Err M }\end{array}$ \\
\hline Post-test & & & & \\
\hline Exp Group & 11 & 80.55 & 14.49 & 4.6 \\
\hline Control Group & 11 & 75.82 & 14.80 & 4.3 \\
\hline
\end{tabular}

From table 4, we can see that the groups have no significant difference in pre-test results, with a difference 1.91, so we can say that the level of participants in general is the same for the two groups. This fact is important for the analysis of the results in the post-test, as we compare the control group which had traditional teaching with the experimental group which participated in experimental lessons using computer program. It is important as well that the two groups have no significant difference in the computer technology knowledge level. Given that the maximum of scores in the pre-test was 100 points, the knowledge level of participants in both groups regarding the mathematical content tested can be defined as a good level, as their average scores are $70-72$. As mentioned in the design of instruments, one of the aims of the pre-test was to relate the participants learning to prior knowledge, which would be upgraded during the lessons with the new content. For this reason it is an important fact that both groups had good performance in this test. Meanwhile, in table 5 we present that the experimental group has higher mean compared to the control group, with a difference of 4.73. This shows an important result for the study, as we can say that the experimental group had better performance than the control 
group in the post-test.

\subsection{The Responses to the Questionnaire of Attitudes Toward Using Computer Program in Learning Computer} Technology

As already described in the chapter on methods, one of the instruments was a questionnaire about the attitudes toward using computer program during the computer technology lessons. There were 11 items in this questionnaire, which are listed and analyzed. The positive statement related to the use of the program is noted in underline, and the negative expressions are noted in bold.

1. Computing power makes it easier to explore computer technology ideas.

2. I know computers are important but I don't feel I need to use them to learn computer technology.

3. Computers and graphics calculators are good tools for calculation, but not for my learning of computer technology.

4. I think using technology is too new and strange to make it worthwhile for learning computer technology.

5. I think using technology wastes too much time in the learning of computer technology.

6. I prefer to read a text book by myself, without using a computer or graphics calculator.

7. Using technology for the calculations makes it easier for me to do more realistic applications.

8. I like the idea of exploring computer technology lessons and contents using technology.

9. I want to get better at using computers to help me with mathematics.

10. The symbols and language of computer technology are bad enough already without the addition of technology.

11. Having technology to do routine work makes me more likely to try different methods and approaches.

Table 6 lists the points for each student in the experimental group. The mean of points gathered is 41.6 from a total of 55 points, and most students reacted positively and had positive attitudes(Table 7).

Table 6. Points from the evaluation of items of Table 7. Categories of attitudes according to the responses the questionnaire

\begin{tabular}{|c|c|c|c|}
\hline & & & \\
\hline Participant No. & Score & Category & Number of participants \\
\hline 1 & 44 & Excellent & 1 \\
\hline 2 & 38 & Very good & 8 \\
\hline 3 & 41 & Acceptable & 1 \\
\hline 4 & 44 & Barely acceptable & 1 \\
\hline 5 & 44 & Not acceptable & 0 \\
\hline 6 & 42 & & \\
\hline 7 & 41 & & \\
\hline 8 & 40 & & \\
\hline 9 & 32 & & \\
\hline 10 & 49 & & \\
\hline 11 & 43 & & \\
\hline Average / Mean & 41.6 & & \\
\hline
\end{tabular}

From table 7 we can observe that participants mostly had "very good" attitudes related to the use of the program in learning computer technology. Participant 9 had lower points, compared to the others, and is in the category "barely acceptable" attitude. The associated questionnaire completed by this participant contained comments that it was time consuming to develop the program during the lesson and a preference expressed the use of a program in order to construct graphs. Another negative response from the students was that computer technology is complex and difficult enough without adding the computer, and this comment came from a student who had difficulties both in computer technology and in using the computer(participant 2).

\subsection{Analysis of the Interviews}

From the interviews, we can say that most participants found the program easy to use, and that they learned it quickly, but also they mentioned that it would have been better if there was a little more time to practice it and to 
learn how to use it better. Quotations from participants' responses during the interviews and their feedback about the use of the program were as follows:

"I wish I could have more time to learn how to use it and to explore it better"

"I had difficulties to learn how to use the program,

"It helped me drawing graphs and to make calculations"

"It was interesting to solve numeral system in a different way, using the program"

\section{Discussion}

Some of the predominant pedagogical theories such as Constructivism hold that the students should be provided with a teaching and learning environment in which they can 'construct' their own knowledge i.e. a student-centered model. Knowledge construction is of necessity based on 'trial and error'- what works, what did not work etc. In order to provide the necessary feedback to this mode of learning immediate feedback is essential and can be provided by the use of computer technology. However, this paper suggests that computer technology is a tool and for some students may represent a handicap to the learning process. Further work is clearly needed to identify the obstacles to the use of these tools and how to minimize student difficulties.

\section{References}

Ashburn, E. A., \& Floden, R. E. (2006). Meaningful learning using technology: What educators need to know and $d o$. New York: Teachers College Press.

Dewey, J. (1933). How we think: A restatement of the relation of reflective thinking to the educative process. Boston: D. C. Heath and Co.

Duval, R. (1999). Representation, vision and visualization: Cognitive functions in mathematical thinking. Basic Issues for Learning. In Proceeding of the Annual Meeting of the North American Chapter of the International Group for the Psychology of Mathematics Education(21st). Cuernavaca, Morelos, Mexico.

Faugli, B. (2003). Evolution of Education, Theories of Learning and Computer Supported Learning. Høgskolen, Norway.

Grabinger, S., Dunlap, J. C., \& Duffield, J. A. (1995). Rich environments for active learning in action: Problem-based learning. ALT-J, Journal of the Association for Learning Technology, 5(2), 5-17.

Johnson, R. B., \& Onwuegbuzie, A. J. (2004). Mixed Methods Research: A Research Paradigm Whose Time Has Come. American Educational Research Association, 33(7), 14-26.

Jonassen, D. H. (1994). hinking Technology: Toward a Constructivist Design Model. Educational Technology, 34(4), 34-37.

Pea, R. D. (1987). Cognitive technologies for mathematics education. Hillsdale, NJ: Erlbaum.

Skemp, R. R. (1979). Goals of learning and qualities of understanding. Mathematics Teaching, 88, 44-49.

Vygotsky, L. (1978). Mind in society: The development of higher psychological processes. Cambridge: Harvard University Press.

Wilson, S. J. (2008). Dynamic Web Tools for Trigonometry. Innovations in Math Technology, 18.

\section{Copyrights}

Copyright for this article is retained by the author(s), with first publication rights granted to the journal.

This is an open-access article distributed under the terms and conditions of the Creative Commons Attribution license(http://creativecommons.org/licenses/by/4.0/). 